\title{
O CÓDIGO ADMINISTRATIVO DO ESTADO NOVO: A DISTRIBUIÇÃO JURÍDICA DO PODER POLÍTICO NA DITADURA
}

The administrative code of the "Estado Novo": the juridical distribution of political power during the dictatorship

\author{
WALTER GUANDAlini JR. E ADRIANO CODATO
}

http://dx.doi.org/10.1590/S2178-14942016000200009

Walter Guandalini Junior é doutor em Direito do Estado pela Universidade Federal do Paraná (UFPR) e professor do Departamento de Direito Privado no Setor de Ciências Jurídicas da Universidade Federal do Paraná (UFPR) (prof.walter.g@ gmail.com).

Adriano Codato é doutor em Ciência Política pela Universidade Estadual de Campinas (UNICAMP) e professor de Ciência Política na Universidade Federal do Paraná (UFPR). É editor da Revista de Sociologia e Política (www.scielo.br/rsocp) e coordenador do Observatório de Elites Políticas e Sociais do Brasil (http://observatory-elites.org/) (acodato@terra.com.br).

Artigo recebido em 30 de abril de 2015 e aprovado para publicação em 15 de junho de 2016. 


\title{
Resumo
}

0 artigo discute as duas versões do Decreto-Lei 1.202/39 e suas alterações durante o Estado Novo (através do Decreto-Lei 5.511/43 e do Decreto-Lei 7.518/45). Analisamos os diferentes formatos da disposição jurídica que definiu tanto os poderes formais das oligarquias estaduais depois da Revolução de 1930, quanto a agenda político-burocrática dos Departamentos Administrativos dos estados. Trata-se de avaliar a capacidade legal desses aparelhos para formular políticas e tomar decisões, precondição para entender seu poder de agenda. A análise dessa legislação permite compreender como a divisão do trabalho político e burocrático operava no Estado ditatorial, as conexões entre os seus centros de poder e a distribuição do poder pelas oligarquias.

Palavras-Chave: Estado Novo; regime ditatorial; Decreto-Lei 1.202; Departamentos Administrativos; Getúlio Vargas.

\begin{abstract}
This paper examines the two versions of the Decree 1.202/39 and its amendments during the Estado Novo dictatorship (Decrees 5.511/43 and 7.518/45). It analyzes the different formats of the legal provision that set the formal powers of the state oligarchies after the Revolution of 1930 and the political-bureaucratic agenda of the Administrative Departments of the states, evaluating their legal capacity to formulate policies and make decisions, as a precondition to understand their power of agenda-setting. This analysis explains how the division of political and bureaucratic work operated in the dictatorial state, the connections between its centers of power and the distribution of power among oligarchies.
\end{abstract}

KeYwords: "Estado Novo"; dictatorial regime; Decree 1202; Administrative Departments; Getúlio Vargas

\section{RÉSUMÉ}

L'article décrit les deux versions du Décret 1202/39 et ses amendements au cours de la dictature de l'Estado Novo (décrets 5511/43 et 7518/45). On analyse les différents formats de la disposition légale qui a établi les pouvoirs officiels des oligarchies de l'Etat après la Révolution de 1930 et l'agenda politico-bureaucratique des services administratifs des Etats. Donc on peut évaluer leur capacité juridique de formuler des politiques et de prendre des décisions, condition préalable à comprendre leur pouvoir de agenda-setting. L'analyse de la législation nous permet de comprendre comment la division du travail politique et bureaucratique opérait dans l'état dictatorial, les connexions entre leurs centres de pouvoir et la répartition du pouvoir entre les oligarchies.

Mots-ClÉs: "Estado Novo"; régime dictatorial; Décret 1202; départements administratifs; Getulio Vargas 


\title{
INTRODUÇÃO
}

\begin{abstract}
Não admitiremos a "constituição de uma espécie de parlamento de técnicos com exclusão de políticos, ou uma assembleia de classes com a missão de legislar sem outra preocupação doutrinária que a de transladar para as leis, na sua pureza doutrinária, sem o menor esforço para adaptá-los às exigências da vida social, os princípios científicos e as concepções unilaterais dos especialistas de vários tomos".
\end{abstract}

Do Editorial de O Estado de S. Paulo, 21 jun. 19321

$\mathrm{E}$ m 10 de abril de 1939 o Estado Novo publicou o Decreto-Lei 1.202 que dispunha, como informava sua ementa, "sobre a administração dos Estados e Municípios". 0 texto do decreto previa, em seu art. 1, que a regulamentação servisse como substitutivo das Constituições estaduais. ${ }^{2}$ Ao fazê-lo, violava a Carta do golpe de Estado de novembro de 1937, que atribuía aos governos estaduais a competência para outorgar suas próprias constituições. ${ }^{3}$ Sob uma justificativa legalista, fundamentava implicitamente a transgressão no fato de após quase dois anos ainda não ter sido realizado o plebiscito que fora previsto pelo art. 187 da Constituição Federal, embora a sua vigência não fosse condicionada à consulta popular. ${ }^{4} \mathrm{Em}$ abril de 1939 o ministro da Justiça Francisco Campos, redator do decreto, apresentava essa desculpa:

Durando a intervenção até a posse dos governadores eleitos, era necessário não só fixar um limite para a promulgação das constituições estaduais, como ainda, organizar, até esse termo, o regime de intervenção. Do contrário, teríamos, por um lado, a possibilidade de coexistirem dentro do País unidades dotadas de constituição nova e unidades em pleno regime de intervenção e sujeitas à interferência dos antigos textos constitucionais e das leis orgânicas locais neles inspiradas; e, por outro, uma descontinuidade de ação, incompatível com o sistema jurídico dos arts. 176 e 180 da Constituição.

Num momento em que a união nacional é, para todos os povos, questão de vida e de morte, seria um contrassenso que o Brasil assim fragmentasse a sua própria unidade, que é motivo dominante do processo de sua formação histórica. Este o sentido da norma inscrita na Constituição e que o Decreto-Lei no 1.202 não fez mais do que desenvolver e sistematizar. 
Referendada que seja, pelo voto plebiscitário, a Constituição Federal, terão os estados a oportunidade de votar, dentro dos princípios e da forma da Constituição nacional, as suas próprias leis constitucionais. Até então, porém, deverão ser governados - ou, mais exatamente, administrados - de acordo com um só padrão assentado pelo Presidente da República, a quem o art. 180 da Constituição confere a responsabilidade total do bem público e de toda a vida da Nação, e que, portanto, necessita de um instrumento adequado para colimar os seus fins e fazer chegar a sua vontade pessoal a todos os pontos do país (Campos 2001, p.111).

O "Código Administrativo", como ficou conhecido o decreto, distribuiu as funções governativas nos estados entre duas entidades político-burocráticas: a Interventoria Federal, de um lado, como o Poder Executivo, e o Departamento Administrativo, como um sucedâneo de Poder Legislativo regional. Os interventores, segundo o arranjo político que resultou das definições de Getúlio Vargas e Francisco Campos, teriam garantido o poder de nomear os prefeitos municipais, indicar seus secretários, constituir ou destituir funcionários públicos e administrar seus estados por decreto, sendo nomeados pelo presidente da República com a referenda do ministro da Justiça e Negócios Interiores. Os membros do Departamento, por sua vez, seriam escolhidos diretamente pelo presidente da República ${ }^{5}$ e deveriam examinar todos os decretos-lei baixados pelo interventor ou pelos prefeitos, além dos projetos de orçamento e a execução orçamentária do estado e dos municípios. ${ }^{6}$

A implementação dos Departamentos Administrativos dos estados não foi consensual, apesar de todo o poder ditatorial reunido na Presidência da República por Vargas. Nesse contexto institucional, qualquer movimentação no organograma político-administrativo provocava toda sorte de conspirações e especulações palacianas. Maciel Filho, em seu jornal O Imparcial, procurou repercutir as críticas ao Decreto-Lei 1.202 e em carta pessoal ao presidente expôs sua "divergência total" com Francisco Campos, ministro da Justiça e o inventor da mudança na estrutura política do regime. A Lei Orgânica de Estados e Municípios seria um dos capítulos centrais da atividade legiferante casuística, elaborada por "advogados perigosos" reunidos na "Comissão de Revisão dos Projetos de Lei" criada pelo Decreto-Lei 1.019/1938, e comandada por Francisco Campos. ${ }^{7}$

0 objetivo deste artigo é verificar como as sucessivas alterações promovidas no Decreto-Lei 1202/39 podem nos ajudar a estabelecer as conexões entre a dinâmica dos interesses políticos e a dinâmica do universo burocrático durante o Estado Novo.

As relações entre o processo político, o processo decisório e o reordenamento das facções da elite daí decorrentes podem ser explicadas mediante duas noções muito operacionais propostas por Anthony Giddens: 'relevância institucional' do aparelho (entre os aparelhos do Estado) e 'hierarquia' política entre os diferentes grupos de elites (que formam o universo político): 
Ao determinar o predomínio relativo dos grupos de elite em termos da sua posse do poder, há dois fatores centrais que devem ser levados em consideração: vou me referir a eles como a natureza da hierarquia que existe entre grupos de elite e a relevância institucional das formas de organização social ou da instituição [política ou burocrática] que eles comandam. 0 primeiro fator está intimamente relacionado a um aspecto do poder indicado anteriormente: o grau de importância dos problemas chave controlados pelos grupos de elite. Existe uma hierarquia entre grupos de elite quando um grupo (por exemplo, a elite política) possui poder sobre questões mais decisivas do que aquelas determinadas por outros e, por isso, é capaz de exercer em grau maior ou menor um controle sobre esses últimos. A "relevância institucional" refere-se à dimensão vertical do poder: a idéia pode ser definida pelo grau em que uma dada instituição afeta as oportunidades de vida do conjunto de indivíduos que pertencem a ela (Giddens, 1974: 8).

Hierarquia entre elites ou entre grupos de elite está diretamente conectada a "poder de agenda": um grupo político que consegue decidir sobre temas mais importantes submete um outro que não tem, mesmo formalmente, o mesmo "poder", isto é, que não controla o mesmo tipo e o mesmo volume de recursos políticos, burocráticos etc., cujas decisões não têm o mesmo raio de ação, e cujas ações não exercem a mesma influência sobre os demais grupos. Esse critério objetivo (pois permite medir a capacidade política dos agentes através dos temas de política que chefiam) desloca a classificação do poder relativo das facções da elite da definição formal das competências dos aparelhos que elas controlam (via legislação), ou da situação/conexão social dos decisores para o âmbito específico do processo decisório. Por essa ideia existe assim um paralelismo estrito entre a hierarquia da elite (elites nacionais, elites regionais; e, dentro dessa última, alta, média e baixa oligarquia) e a hierarquia dos assuntos governados por ela. Assim, conforme a proposição de Giddens, a ordem de importância sobre o que se decide rege a ordem de importância de quem decide - ou é, ao menos, um índice do seu poder efetivo.

Relevância institucional diz respeito à natureza da instituição que um grupo (político, no caso) comanda e conduz e, mais especificamente, ao valor estratégico dessa instituição para uma dada sociedade (no nosso caso, para uma configuração institucional particular). Sua autoridade, prestígio ou influência ("institutional salience") pode ser estimada, objetivamente, em função das chances políticas que faculta aos agentes que fazem parte dela. Para os nossos fins, esse indicador, menos preciso que o primeiro, arrasta a definição e a delimitação da quantidade de poder da posição protocolar que o aparelho ocupa no organograma (ou que uma instituição detém no sistema social, o sentido original da definição) para o terreno do processo político-burocrático. Por essa ideia, deduz-se, a importância estratégica de uma agência é função ora da dinâmica política mais geral (o que indica que se olhe também para 
fora do circuito decisório), ora da batalha entre os agentes (burocráticos e políticos, no caso) no interior do circuito decisório pelo poder de definir a própria agenda e a dos demais, pelo poder de decidir ou de adiar uma decisão, impedir sua execução, modificar seu conteúdo no momento da implementação e assim por diante.

Em resumo: instituições importantes e decisões importantes tornam, ipso facto, a elite importante. As duas variáveis pegadas são decisivas para decidir, de acordo com o raciocínio de Giddens, as posições ocupadas pelos diferentes grupos políticos no universo das classes dirigentes. 0 que é essencial reter dessa perspectiva analítica é que o estudo do mecanismo de tomada de decisões (suas regras legais, seus procedimentos, seus aparatos) são procedimentos estratégicos para descobrir tanto o valor da instituição onde se decide, quanto a autoridade da elite que a pilota.

O conhecimento mais circunstanciado da legislação política da ditadura varguista exige que se abandone o ponto de vista dos macroprocessos (a relação, um tanto vaga, entre "Estado-e-sociedade"), para focalizar o quadro legal que delimita, através das disposições sobre as estruturas internas do aparelho do Estado discutidas a seguir, as interações entre os agentes políticos e os agentes burocráticos.

0 que é característico do regime ditatorial do Estado Novo é que a promoção de quaisquer agentes políticos ao sistema político só pode ser feita mediante seu ingresso no sistema decisório, única porta de entrada para o "campo do poder" (Bourdieu 1989). Mesmo aí, a quantidade e a qualidade de poder que cada agente controla vai depender da forma de organização burocrática do sistema de tomada de decisões: é ela quem comanda tanto o tipo de tema de política com o qual se lida, quanto o alojamento de uma ou outra facção da elite política num ponto determinado da cadeia decisória. Esse fato básico impõe, por si só, um estudo descritivo das disposições legais do Estado ditatorial.

\section{O Código Administrativo do Estado NOVO E OS JURISTAS DA DITADURA}

doutrina jurídica sobre o Decreto-Lei 1.202 é escassa. Durante os seis anos de exis-
tência da "Lei Orgânica dos Estados e Municípios", o outro nome desse código da ditadura, os administrativistas parecem ter tido mais interesse em compreender os princípios imutáveis da teoria europeia sobre a administração do País (i.e., a dogmática jurídica abstrata) do que em analisar os decretos inconstantes do ditador brasileiro sobre a administração dos estados. Além disso, a ideologia centralista do regime tendia a reduzir a importância dos estados em face da União, adotando uma doutrina municipalista que situava no plano local, 
e não no regional, as perspectivas de participação popular na unidade nacional. 0 exemplo emblemático é o estudo de Djacir Menezes (1943) sobre "os princípios estruturais do Estado Nacional na administração pública": embora o professor do todo-poderoso DASP dedique vários capítulos de seu livro à prática de descentralização administrativa, e um em especial à descentralização territorial, sequer menciona os "entes federados", limitando-se a analisar o papel desempenhado pelos municípios na formação do Estado brasileiro.

Os poucos autores que se dedicaram a analisar o Código Administrativo da ditadura têm opiniões contraditórias. As diferenças não parecem ser motivadas pelas alterações realizadas no texto do Decreto-Lei 1.202 (discutidas em detalhe na sequência), mas sim por uma compreensão distinta do significado e do papel desempenhado pelos Departamentos Administrativos na estrutura do Estado brasileiro.

Ainda em 1939, logo após a publicação do DL, Francisco Campos definia o Departamento Administrativo como "órgão de colaboração legislativa e de fiscalização da execução orçamentária" (2001:110) da Interventoria, ressalvando que a bipartição de atribuições não era uma distribuição dos poderes do Estado, mas "simples e natural divisão de trabalho" - até porque "só existe, atualmente, no País, um Poder Legislativo e Executivo, que é o Presidente da República" (2001: 112).

Escrevendo alguns anos depois, sob a égide da retificação de junho de 1939, Tito Prates Fonseca (1942) considerava que o Departamento Administrativo não desempenhava funções legislativas, atuando como órgão consultivo da Interventoria ao emitir pareceres com caráter vinculante. Assim, enfatizava a "boa impressão" causada pela "instituição e regulagem equilibrada desse sistema", que julgava "uma experiência interessantíssima" (Fonseca, 1942: 34). Em 1945, já no apagar das luzes do regime estadonovista, Gessner Pompílio de Barros (1945) considerava que os "Conselhos Administrativos" (nomenclatura adotada pelo Decreto-Lei 5.511 de 21 maio 1943) ${ }^{8}$ representavam uma limitação de natureza administrativa à autonomia dos estados-membros, atuando como "espécie de controle e orientação da administração do Estado" pelo governo central (Barros, 1945: 79). No entanto, o mesmo autor, algumas páginas depois, indicava esses Conselhos como exemplo de "articulação administrativa" entre os estados-membros e o governo central, a caracterizar o federalismo puro que "estreita os laços de dependência espontânea pelo estabelecimento recíproco de interesses que se conjugam", definindo-os como "órgãos auxiliares de cada governo estadual na sua administração e na municipal" (Barros, 1945: 84 e 86).

Uma leitura contemporânea do decreto induz a conclusões diversas. Apesar da opinião abalizada dos autores, o seu texto parece indicar o desempenho de funções um pouco distintas, principalmente de fiscalização e controle administrativo dos atos praticados pelo 
interventor ${ }^{9}$ - 0 art. 17 se refere somente à "aprovação" dos decretos-lei, e apenas as suas duas últimas alíneas são reservadas à função consultiva mencionada. Além disso, a apreciação da Lei Orgânica da política ditatorial sugere que a manutenção da "regulagem equilibrada" dessa "natural divisão do trabalho" talvez fosse um pouco mais complexa do que a imagem idealizada por Fonseca (1942). Desde a criação do decreto, e até os últimos momentos do regime, a legislação para a administração dos estados e dos municípios foi objeto de uma querela mais ou menos intensa entre seus protagonistas: as suas alterações sucessivas em 1939, 1943, e $1945^{10}$ sugerem como (e por que meios) esse sistema decisório foi se constituindo e qual a conveniência desses instrumentos institucionais para o regime político; ou por outra: como sua serventia "administrativa", apreendida aqui através da noção de "relevância institucional" (tal como definida acima), foi se adaptando em meio à trama das relações políticas e burocráticas entre os agentes do sistema.

Apesar das intenções explicitadas pelos artífices do novo regime, a extinção das instituições representativas não foi capaz de extinguir a política, agora dissimulada como técnica administrativa. Contra todas as aparências, tendo burocratizado ao máximo as relações políticas entre os agentes, o Estado de exceção não só transferiu para a ordem jurídica a definição de suas prerrogativas, mas, antes de tudo, transformou o terreno legal num dos únicos locais possíveis para a sua disputa. A ditadura do Estado Novo promoveu a politização da técnica que se pretendia neutra: com isso a legislação administrativa perdeu seu caráter relativamente autônomo em relação ao debate político e se tornou, em vez de formalização dos resultados da disputa pela distribuição do poder de governo, o próprio campo no interior do qual essa disputa ocorria.

\section{A ReTIFiCAÇÃo DE 13 DE JUNHO: FORTALECIMENTO DA INTERVENTORIA}

$\mathrm{E}$ m 13 de junho de 1939 o Decreto-Lei 1202/39 sofreu sua primeira "retificação". A alteração legislativa não foi realizada através de revogação ou derrogação por novo decreto, mas por mera "republicação" do texto do decreto original, com o mesmo número, acrescido das correções reputadas necessárias. Em entrevista concedida em 28 de julho um defensivo Francisco Campos se justificava:

A Lei Orgânica dos Estados foi republicada. Haviam escapado à revisão pequenos senões, que era preciso corrigir. E não se faça carga de lapsos dessa espécie à legislação do Estado Novo, quando há cochilos de redação no próprio Código Civil, sobre o qual passaram, anos a fio, os olhos de mais eminentes e decorativos juristas, legisladores e filólogos que já viveram neste 
País. Quando que bonus... Mas não se alterou a essência do Decreto-Lei ํำ1.202, e tenho a certeza de que ele prestará à nação, aos estados e aos seus governos um serviço inestimável (Campos 2001: 158).

Segundo Francisco Campos, a correção dos "pequenos senões" não modificou a essência do decreto, que manteve o seu objetivo fundamental de centralização política (mas não administrativa, enfatiza). A Lei Orgânica é enaltecida como instrumento de realização da "unidade e continuidade de ação" necessárias para a correção dos "erros inveterados" do passado, permitindo que os esforços dos estados finalmente se articulem "num todo harmonioso, para o bem do Brasil, de cada uma das suas unidades e de cada um dos seus filhos".

0 defeito mais recorrente dos enfoques sobre a legalidade do exercício do poder (legalidade entendida aqui como 'em conformidade com as prescrições da lei', seja ela legítima ou não) é a tentação das leituras formalistas ou juridicistas dos códigos de Direito: para essas interpretações uma sociedade funciona - e pode, portanto, ser explicada - a partir das disposições legais que regulam suas relações sociais; ao invés de admitir que o político engloba o jurídico, sendo a legislação a cristalização dos conflitos do mundo social, supõe-se o contrário: que o jurídico engloba o político.

A perspectiva aqui adotada é contrária a essa: os marcos legais dispõem sobre o que é politicamente possível e o que não é; o que é aceitável e o que não é na disputa pelo poder; 0 que lícito ou ilícito no exercício do poder, etc. 0 jurídico fixa os limites políticos da ação política dos agentes, embora quem defina a capacidade do jurídico de fixá-los seja a própria política (isto é, os conflitos reais entre os agentes).

Entretanto, como aparentemente não há, nesse regime, "política" - isto é, como não há uma esfera política completamente autônoma onde os interesses se constituam e se enfrentem de maneira aberta -, as disputas pelo poder se dão também, e às vezes principalmente, no terreno jurídico-político; sendo a Constituição mera formalidade no que se refere ao capítulo "divisão dos poderes", todas as diferenças se dão mais exatamente em torno da "legislação administrativa": como interpretá-la, como aplicá-la, quando mudá-la, se se deve mudá-la, em que sentido etc. Por isso, o que dá a impressão de ser um torneio hermenêutico é na realidade uma luta por ver fixado num decreto-lei para sempre os recursos políticos à disposição de um determinado agente. Essa segurança jurídica é, no contexto, o antídoto tanto contra o "arbítrio" (a administração personalista), quanto contra a "desordem administrativa" (a confusão de poderes).

À primeira vista, uma das diferenças principais entre as duas primeiras versões do "Código dos Interventores" (a de abril e a de junho de 1939) diz respeito à diminuição do poder 
do ministro da Justiça, cujas atribuições para superintender, dirigir e comandar o novo sistema que ligava entre si os aparelhos políticos do Estado ditatorial foram sumariamente canceladas e transferidas, por pressão direta dos próprios interventores, para o presidente da República - que se tornou titular das competências para conferir efeito suspensivo aos recursos contra os atos do interventor, ${ }^{11}$ revogar o efeito suspensivo concedido pelo Departamento Administrativo $^{12}$ e analisar os relatórios de gestão elaborados pelos interventores. ${ }^{13}$

Mudar o desenho político-institucional do regime, pouco mais de um ano depois do golpe de Estado de 1937, reduzindo o poder de decreto dos interventores, não foi uma tarefa isenta de conflitos. Do momento em que o Código dos Interventores começou a ser tratado em despachos com o ministro da Justiça, em 16 de janeiro, até sua publicação no Diário Oficial, em 10 de abril de 1939, houve movimentações políticas para garantir que os interventores estaduais não tivessem suas prerrogativas políticas rebaixadas. Uma vez publicado o decreto-lei, Vargas anota em seu Diário que os comandantes estaduais ficaram "um pouco apreensivos" com a nova legislação. 0 governador de Minas Gerais foi um dos que demonstraram, diz Vargas, maior "má vontade" com o Código Administrativo. Cordeiro de Farias, interventor no Rio Grande do Sul, ameaçou até mesmo renunciar "se não fossem atendidas suas ponderações" para que os Departamentos Administrativos se convertessem em apenas órgãos consultivos, sem poder de veto. 0 chanceler Osvaldo Aranha avisou que iria exonerar-se caso a Lei Orgânica dos Estados não fosse revogada. ${ }^{14}$

Em face do poder central os interventores conquistaram também maior liberdade para a gestão de seu corpo de funcionários com a inclusão das exceções ao art. 40, ${ }^{15}$ que em sua versão anterior vedava completamente o exercício de funções públicas por estrangeiros - proibição a que Campos concedia bastante importância, de forma consentânea com o nacionalismo que permeava a ideologia do regime:

No artigo 40, a lei enfrentou um problema cuja gravidade se faz sentir em toda parte do País, em algumas regiões se tornou extrema. Falo do acesso de estrangeiros a cargos públicos. Os cargos públicos foram sempre, por definição constitucional, privativos dos brasileiros. Mas as infrações a esse preceito foram também sempre numerosas, e quase sempre de má-fé. Quando as disposições relativas aos cargos efetivos se tornaram mais rigorosas, o recurso dos contratos de técnicos e, frequentemente, de falsos técnicos, foi um meio de burlar a exigência legal e constitucional. Assombra a facilidade com que se alojam estrangeiros nos serviços públicos repetindo o que se dá nas empresas particulares - quando todos conhecemos as dificuldades que encontram, para colocar-se, numerosos moços brasileiros de mérito. Nós temos que acabar com esse estúpido preconceito que vê uma sumidade em cada "técnico" estrangeiro (Campos 2001: 114). 
No entanto, quando se examina mais de perto, a questão mais importante e que exigirá a republicação do decreto-lei é outra: é a da luta pela preservação de alguns dispositivos de poder dos interventores que os Departamentos corriam o risco de tirar. Até se chegar a um consenso sobre a divisão do trabalho político entre os aparelhos políticos do Estado, os interventores tiveram de brigar em duas frentes, simultaneamente: de um lado, para não serem monitorados por um "mero" ministro (e, no caso, a disputa não era anônima, visto que, de acordo com a lógica personalista que anima esse sistema decisório, o ministro Francisco Campos, ao inventar o decreto, pretendia garantir para si o poder arbitral entre os conselheiros dos Departamentos e os comandantes das Interventorias); e, de outro, para não perderem funções políticas relevantes que já detinham para a nova agência. Vencida a primeira batalha, na segunda o ganho foi limitado: a variante do art. 60 rezava que só "em caso da calamidade ou necessidade de ordem pública", i.e., em caso de crises políticas, o Executivo estadual não precisaria submeter suas decisões (os decretos-leis), antes de publicá-las, ao Departamento Administrativo; ${ }^{16}$ o 9o, por sua vez, despachava para uma "lei especial", que ainda não havia, os crimes de responsabilidade dos interventores federais, ${ }^{17} 0$ art. 12 passava a condicionar a aprovação dos orçamentos municipais pelo Departamento Administrativo à revisão prévia pelos interventores; ${ }^{18}$ por último, no artigo 17 os interventores conseguiram permutar a palavra "determinar" por "propor", atribuindo caráter meramente opinativo às propostas de modificação na estrutura dos estados elaboradas pelo Departamento Administrativo, e incluir um parágrafo único que conferia ao interventor o direito de recorrer de suas decisões ao presidente da República. ${ }^{19}$ Uma mudança curiosa foi a da redação do art. 14, sobre o período de quarentena dos nomeados para o Departamento que deixassem a posição: abolido sumariamente, junto com suas severas penalidades. ${ }^{20}$

Os desenhos distintos das relações possíveis de dominância e subordinação entre Interventorias, departamentos e o ministro Francisco Campos em pessoa em 1939 demonstram a íntima relação existente entre as modificações da legislação administrativa e o problema da disposição dos agentes pelas posições do campo burocrático. 0 caso é que, em grande medida, o campo burocrático no Estado Novo às vezes as intercepta num ponto crucial, às vezes as engloba, às vezes sobrepõe-se e às vezes confunde-se totalmente com o campo político. Assim, a disputa pela primazia no processo decisório (quem governa o quê?), e até mesmo em decisões à primeira vista menores - disposições ordinárias, regulamentos administrativos etc., como era o caso da pauta do Departamento Administrativo (como ele tinha de revisar todos os decretos, todos significa tudo) - é, nesse contexto, estratégica, já que em muitos casos pode ser a única fonte de poder político, ou mais exatamente: o único meio (burocrático, no caso) de fazer política que restou à oligarquia. 


\section{O DECRETO-LEI 5511/1943: FORTALECIMENTO DOS DEPARTAMENTOS ADMINISTRATIVOS}

$\mathrm{E}$ m 21 de maio de 1943 a Lei Orgânica dos Estados foi mais uma vez submetida a uma profunda reorganização, dessa vez por intermédio de novo decreto: o Decreto-Lei 5511/1943. A remodelação parcial do sistema departamentos-interventorias foi um meio para estender o poder burocrático dos Departamentos Administrativos, e um sintoma da necessidade de controlar melhor o poder político dos interventores federais nos estados. Como se verá adiante, a reforma principal que o Decreto-Lei 5511 introduziu nesse arranjo não foi a mudança - ideológica e publicitária - na denominação do "Departamento" para "ConseIho", a fim de sugerir seu papel como uma câmara ao mesmo tempo política e legislativa do regime, ${ }^{21}$ em oposição ao nome típico de repartição pública; não foi também a licença para que os professores universitários pudessem participar dessa egrégia assembleia. As alterações fundamentais foram: a confirmação da subordinação das decisões dos executivos estadual e municipal aos Departamentos e o aumento da sua capacidade política para enquadrar prefeitos e interventores que não cumprissem suas disposições.

Como os Departamentos, no fim das contas, estavam subordinados ao presidente da República, a medida significava simplesmente um reforço da política de centralização num momento em que a democracia voltava a empolgar alguns. Nesse sentido, o ponto central da minirreforma administrativa são as alterações realizadas nos artigos 6ำ e 17 do decreto original. 0 artigo 6으 que estabelecia as competências administrativas do interventor, passou a condicionar grande parte das suas prerrogativas à aprovação prévia pelos Departamentos (organizar o orçamento do estado, fixar o efetivo da força policial, expedir decreto-lei); ${ }^{22}$ e 0 artigo 17, que estabelecia as competências administrativas dos Departamentos, passou a lhes conferir a prerrogativa de inserir emendas nos decretos-leis do interventor e no orçamento do estado, e de opinar nos projetos submetidos ao presidente da República, cominando com nulidade todos os atos praticados pelo interventor (que também perdeu o direito de recorrer ao presidente) em contrariedade com a sua decisão ou sem a sua manifestação. ${ }^{23}$ Este era 0 ponto central da minirreforma administrativa.

As modificações principais foram as seguintes:

- Sobre os poderes dos interventores (art. 6ำ): a preparação do orçamento foi transferida para a sucursal do Departamento do Serviço Público (DASP) em cada estado; a sanção do orçamento estadual e a fixação do efetivo da força policial (recurso mais que estratégico) passaram a depender da anuência prévia do Departamento Administrativo; e o poder de redigir decreto-lei tornou-se o poder de redigir projeto de decreto-lei, que só entraria em vigor mediante exame e depois de publicado o parecer final pelo Departamento Administrativo. 
- Sobre os poderes dos Departamentos Administrativos dos estados (art. 17): poderiam emendar (isto é, modificar) projetos de orçamento e projetos de decretos-leis decididos por interventores e prefeitos; poderiam também opinar sobre eles, quando o assunto fosse de alçada do Chefe Nacional. As outras medidas diziam respeito aos prazos dos recursos e de manifestações, novamente reforçando os poderes do Departamento ao exigir que prefeitos e interventores se manifestassem expressamente sobre as propostas e pareceres que viesse a emitir ( $\S 10$ a 8 ํ). 0 comentário adicional que se poderia fazer sobre suas novas competências é talvez o já anotado por Camargo: além do sentido político evidente (o Departamento passa, segundo ele, "a integrar de forma mais efetiva e direta a administração", a ponto de exercer "funções de verdadeiro Conselho Político de Estado"), há um aspecto "jurídico-formal" importante no novo Código dos Interventores: essas "alterações procuram o aperfeiçoamento técnico das disposições do decreto-lei 1202, adequando-as às regras gerais da técnica legislativa, na busca da racionalização da lei" (Camargo 1983: 58).

Pode ser. Os conflitos em torno da agenda burocrática enfatizam um aspecto diferente.

0 fato de a pauta dos Departamentos ser inespecífica - o Presidente do DAESP, depois de um ano de existência comemorou "a soma incalculável de trabalhos" que a agência realizou: "trabalhos de toda sorte. Trabalhos de extrema complexidade e, não raro de grande transcendência, pois que disseram respeito, na multiplicidade dos assuntos tratados, a toda a ordenação administrativa do estado" 24 - era a fonte da sua força burocrática (e, por extensão, da sua força política relativa, já que, às vezes, as duas ordens de problemas se misturavam). Era também, por outro lado, a razão da limitação da sua ação política: se podiam legalmente vetar as iniciativas do interventor, estavam impedidos, por outro lado, de propor leis, ou decretos com força de lei. Como se imagina, essa barreira não apaziguava a vontade de poder dos seus integrantes, e essa se tornou, ao longo de tempo, e mesmo depois desse novo decreto, uma questão assumida e liderada em particular pelo Departamento de São Paulo.

Na passagem do sexto aniversário do "Estado Nacional" (novembro de 1943) realizou-se no Palácio Monroe no Rio de Janeiro o "Congresso dos Conselhos Administrativos dos estados". Reunidos os delegados de todos os Departamentos estaduais, Getúlio Vargas havia orientado os debates para que se modificassem algumas disposições do decreto-lei original. O propósito era aliviar a agenda presidencial, o que exigia que "muitas das proposições que hoje [vinham] ao seu conhecimento, ficassem reservadas tão somente ao âmbito dos poderes estaduais" ${ }^{25}$ Examinaram-se no Congresso 143 proposições, elaboradas a partir de quatro comissões: comissão de orçamento, comissão sobre terras e tributos, comissão sobre recursos (das decisões dos Departamentos Administrativos) e comissão administrativa. Representaram São Paulo o presidente da agência, Gofredo Telles, e Cirilo Junior. No discurso do ministro da 
Justiça e Negócios Interiores, Marcondes Filho ressaltou o papel dos Departamentos "para a formação de uma consciência administrativa no País, tanto em relação aos municípios, [...] como em relação aos estados". Mantida, segundo sua opinião, uma "justa autonomia" entre todos os aparelhos do Estado, "os Conselhos [Departamentos]" haviam "desenvolvido notável trabalho, conseguindo que a disciplina das semelhanças prevaleça sobre a teimosia das diversidades".26

São Paulo apresentou o maior número de propostas. Sua ação fixou-se em questões de metodologia e técnica para dotações orçamentárias, na simplificação dos procedimentos ordinários (a fim de suprimir a "dualidade de funções legislativas") e na eliminação de superposições políticas e burocráticas entre os aparelhos do Estado. 0 caso aqui eram as muitas coincidências nas operações do Departamento Administrativo com o Departamento das Municipalidades, que havia se tornado seu maior rival na atividade de regulação das prefeituras do interior. 0 Departamento das Municipalidades era a agência de que o interventor se servia para controlar politicamente os prefeitos, pois os orçamentos das cidades do estado deveriam obrigatoriamente passar por ele antes de chegar ao Departamento Administrativo. ${ }^{27}$ Sempre em benefício do aumento da agenda e dos poderes dos Departamentos Administrativos, a delegação paulista trabalhou para que pudessem, eles também, propor leis, isto é, para que pudessem ter poder de iniciativa (e não só de veto) no processo legislativo. A moção, no entanto, foi rejeitada pela maioria na votação final. ${ }^{28}$ No fim, nenhuma recomendação do Congresso foi, de fato, implementada.

É razoável especular que o protagonismo paulista fosse aqui resultado de duas coisas. Primeiro, do fato de a delegação paulista ter maior abertura para se expressar. 0 ministro da Justiça, Marcondes Filho, fora vice-presidente do Departamento paulista de 1939 a 1941 (Codato, 2013). Depois, do fato de o Departamento Administrativo de São Paulo ser um dos mais organizados do país (Loewenstein, 1944; Ramos, 1943).

Quando se olha as coisas da perspectiva do processo decisório, o que se repara é que os Departamentos eram originalmente, ou foram imaginados em primeiro lugar para funcionar como, instâncias de informação do sistema: era preciso ter um meio de saber o que se passava nos níveis inferiores da administração e se aquilo que ocorria (a política dos interventores) estava em estrito acordo com as "orientações nacionais": isto é, se o princípio jurídico da centralização funcionava. Recordando que o Decreto-Lei 1202, "uma espécie de carta política do momento" em que fora editado, havia sido "ou minucioso, ou muito radical porque era necessário, senão imprescindível que os poderes federais ficassem bem informados de como estava sendo realizada em detalhes a administração dos estados e municípios", quase cinco anos depois Vargas assentia que havia chegado, enfim, o momento de uma "descentralização 
administrativa" 29 (que, aliás, nunca ocorreu). Ao longo do tempo, os Departamentos que não se tornaram simples apêndices da Interventoria acrescentaram, à tarefa de manter informado o presidente a respeito dos "negócios estaduais", a função de regulação burocrática das ações de prefeitos e interventores, mas sem nunca chegar a ser instâncias de decisão final no sistema. Por ora é suficiente lembrar que, pela legislação em vigor, as únicas demandas dos agentes políticos ao Departamento eram a respeito da legalidade ou da ilegalidade de suas decisões, e aí se concentrava todo o poder de decidir dos DAs.

Na prática, a agenda de uma agência é determinada pela interação entre os agentes "que disputam entre si quais serão os termos da sua cooperação" (Lindblom, 1981: 9), e a luta pelo poder que o Departamento empreendia, e que o episódio relatado logo acima simboliza, revela muito simplesmente a ausência desse poder. Ainda que a percepção comum fosse que esses aparelhos devessem ser tomados sem mais como substitutos das casas legislativas nos níveis federal, estadual e municipal, o ritual "parlamentar" que ao menos o DAESP protagonizava não pode encobrir o fato básico de que, mesmo com todas as funções de superintendência de que podia dispor, ele não detinha a essencial: em primeiro lugar, os Departamentos não produziam "leis", mas resoluções; em segundo lugar, poderiam, no máximo, "propor, do ponto de vista da economia e eficiência", alterações burocráticas em órgãos da administração estadual ou municipal e dar "parecer nos recursos dos atos dos Prefeitos, quando o requisitar, o Interventor, ou Governador" ${ }^{30}$ Nesse contexto, os Departamentos tornaram-se mais uma instância de revisão do que de legislação - ainda que usassem, excepcionalmente, suas prerrogativas legais para introduzir medidas de maior alcance ${ }^{31}$-, sem perder sua atribuição original: informação da atividade política dos escalões inferiores aos escalões superiores da administração nacional.

Olhando somente para o 'Código Administrativo', a diversificação de papéis nesse sistema decisório - instâncias de informação de um lado, instâncias de decisão de outro; certos loci com poder de iniciativa, e outros, diferentes, tão só com poder de veto - corresponde menos à sua "complexidade" ou ao propósito deliberado de dividir o poder de decidir entre os aparelhos, e mais à pretensão de reservar e garantir o poder arbitral do sistema ao "Chefe". É por isso que há, aqui, uma inversão de expectativas: em regra, quanto mais as regras de processamento de iniciativas políticas (as reivindicações dos agentes) e iniciativas burocráticas (as demandas do próprio sistema) são institucionalizadas, menor é o grau de arbitrariedade do sistema decisório ou menos personalista é o processo decisório. ${ }^{32}$ No caso considerado, porém, isso não diminui, antes aumenta o personalismo e o autoritarismo, uma vez que a institucionalização se dá em benefício do aumento do poder (e não da regulação do poder) de um agente político específico: o presidente da República. Mas foi contra esse poder que se realizou a próxima mudança importante introduzida no Código Administrativo. 


\section{O DECRETO-LEI 7518/1945: ENFRAQUECIMENTO DA PRESIDÊNCIA DA REPÚBLICA}

poucos meses do fim da ditadura, em 3 de maio de 1945, foi editado o Decreto-Lei
7518/1945, que realizou a terceira modificação relevante na organização administrativa dos estados e municípios. 0 seu espírito era bem outro. Em primeiro lugar, aliviava algumas regras da relação Departamentos e Interventoria, em benefício desta última: restaurava a competência do interventor para expedir decretos-leis sem aprovação prévia pelo Departamento em casos de calamidade, ${ }^{33}$ e excluía os prazos de manifestação do interventor sobre as propostas de reforma administrativa elaboradas pelo Departamento. ${ }^{34}$

Mas a sua característica mais notável não dizia respeito à relação dos interventores com o Departamento, e sim à sua relação com o poder central, e à diminuição dos poderes da Presidência da República. A transfiguração do art. 32 dá a exata medida do que se quer dizer. Do conjunto de 20 incisos do texto original sobraram apenas nove na redação modificada, e mesmo assim, com restrições: passavam a depender da aprovação do presidente da República somente decretos que dispusessem sobre processo judicial ou extrajudicial; sobre a definição do pequeno produtor; sobre divisão administrativa e organização judiciária; sobre impostos ou taxas de exportação; sobre distribuição de impostos aos Municípios; sobre a concessão de isenções tributárias; sobre impostos ou taxas estaduais e municipais, excetuadas aquelas relativas a serviços industriais; e sobre o Poder Judiciário e as Justiças estaduais. ${ }^{35}$

Como se vê, o Decreto-Lei 7518/45 excluiu da competência da Presidência a maior parte dos temas previstos no texto original, limitando os poderes do presidente da República em matérias decisivas para a configuração do regime ditatorial: desde faculdades genéricas como a manutenção do bem-estar, ordem, tranquilidade e segurança pública (inciso I), até prerrogativas específicas como a censura sobre as atividades artísticas (inciso $X$ ) e a regulamentação do ensino (inciso VII). ${ }^{36}$ Essas medidas, supõe-se, passariam para a alçada do interventor/Departamento Administrativo. Todavia, eles não chegaram a decidir sobre elas porque o Estado Novo acabou em outubro, e a Constituição de 1946 restaurou o sistema federativo.

\section{Conclusões}

U m melhor conhecimento do Estado Novo, do funcionamento geral do burocratismo do regime ditatorial e da sua ciência de governo exige que se estipule não só a distribuição formal do poder nessa estrutura decisória, os lugares das principais agências estatais na cadeia burocrática, mas os papéis exatos dos seus operadores nessa nova ordem política. 
Este artigo é, portanto, uma descrição e uma discussão das duas versões do Decreto-Lei 1.202 de 1939 (a de abril e a de junho) e de suas sucessivas alterações (em 1943 e 1945). Expusemos e analisamos os diferentes formatos das disposições jurídicas que definiram e redefiniram os poderes políticos e a agenda burocrática dos Departamentos Administrativos dos Estados.

A ideia de base do trabalho foi a de que a legislação da ditadura pode ser tomada, para além do seu formalismo característico, como uma via privilegiada, entre outras, para acessar a estrutura de poder (discriminando seus níveis e seus agentes políticos), para descrever e, principalmente, para ressaltar os traços típicos do próprio regime político "varguista": o centralismo, o burocratismo, as diversas camadas político-administrativas do Estado, o personalismo que o caracteriza, etc.

Isto posto, a história das modificações do Decreto-Lei 1.202 permite avaliar, com base na evolução dos regulamentos da ditadura, a capacidade legal - ou, nos termos aqui propostos, a relevância institucional- da própria agência para formular políticas e/ou tomar decisões, precondição para entender seu poder de agenda e, portanto, o poder da elite que a pilotava.

A apresentação pormenorizada, tal como feita aqui, de como se chegou aos diferentes perfis institucionais, às atribuições jurídicas e à competência protocolar dos Departamentos Administrativos dos estados é imprescindível caso se pretenda entender o quadro político do Estado Novo e, em especial, as conexões horizontais e verticais entre os seus centros de poder. Esse passo deve preceder e informar, logicamente, a discussão sobre as oportunidades políticas de seus inquilinos, as funções efetivas desse aparelho no sistema estatal e sua influência no processo de hierarquização dos grupos de elite graças aos temas de política que fiscalizavam.

\section{NotAs}

1 Apud Maria Helena Capelato (1989: 190).

2 Art. 1‥ [Decreto-Lei 1.202/39]: Os Estados, até a outorga das respectivas constituições, serão administrados de acordo com o disposto nesta lei. Parágrafo único. As Constituições estaduais só serão outorgadas após a realização do plebiscito a que se refere 0 art. 187 da Constituição. 0 plebiscito, contudo, nunca foi realizado.

3 Art. 181. [Constituição de 1937]: As Constituições estaduais serão outorgadas pelos respectivos Governos, que exercerão, enquanto não se reunirem as Assembleias Legislativas, as funções destas nas matérias da competência dos Estados.

4 Art. 187. [Constituição de 1937]: Esta Constituição entrará em vigor na sua data e será submetida ao plebiscito nacional na forma regulada em decreto do Presidente da República. 
5 Art. 13. [Decreto-Lei 1.202/39]: 0 Departamento Administrativo será constituído de 4 a 10 membros, brasileiros natos, maiores de 25 anos, nomeados pelo Presidente da República. Dentre eles o Presidente da República designará, no ato de nomeação, o presidente do Departamento e o seu substituto nas faltas e nos impedimentos.

6 Art. 17. [Decreto-Lei 1.202/39]: Compete ao Departamento Administrativo:

a) aprovar os projetos dos decretos-leis que devam ser baixados pelo Interventor, ou Governador, ou pelo Prefeito;

b) aprovar os projetos de orçamento do Estado e dos Municípios, encaminhados pelo Interventor, ou Governador, e pelos Prefeitos, propondo as alterações que nos mesmos devam ser feitas;

c) fiscalizar a execução orçamentária no Estado e nos Municípios, representando ao Ministério da Justiça e Negócios Interiores, ou ao Interventor, ou Governador, conforme o caso, sobre as irregularidades observadas;

d) receber e informar os recursos dos atos do Interventor, ou Governador, na forma dos arts. 19 a 22;

e) proceder ao estudo dos serviços, departamentos, repartições e estabelecimentos do Estado e dos Municípios, com o fim de determinar, do ponto de vista da economia e eficiência, as modificações que devam ser feitas nos mesmos, sua extinção, distribuição e agrupamento, dotações orçamentárias, condições e processos de trabalhos;

f) dar parecer nos recursos dos atos dos Prefeitos, quando o requisitar o Interventor, ou Governador.

7 Bilhete manuscrito de Maciel Filho a Getúlio Vargas. Museu da República. Arquivo Histórico. Arquivo Getulio Vargas - GV cr 940.00.00 GV 04 cr (1).

8 A troca foi uma sugestão de Gofredo da Silva Telles Jr. ao ministro da Justiça, Marcondes Filho. De acordo com Gofredo Jr., assessor informal do presidente do Departamento paulista (Gofredo da Silva Telles), a nova palavra daria uma ideia melhor tanto das funções legislativas (técnicas), quanto das funções representativas (políticas) que o aparelho possuía. Comunicação pessoal. São Paulo, 11 jul. 1996.

9 Art. 17 [Decreto-Lei 1.202/39], alíneas a a d: aprovar decretos-lei, aprovar o orçamento, fiscalizar a execução orçamentária, receber recursos dos atos do interventor.

10 Para uma visão mais clara de todas as modificações (retificações, inclusões, exclusões, alterações maiores e menores) em cada um dos artigos da legislação que regulou o Departamento Administrativo, consultar os Decretos-Leis 1754/39; 1801/39; 1804/39; 2416/40; 5511/43; 7309/45 e 7518/45.

11 Art. 21. [Retificação do Decreto-Lei 1202/39] O Presidente da República [substitui "O Ministro da Justiça" na redação anterior] poderá determinar, em cada caso, que o recurso tenha efeito suspensivo. 0 despacho nesse sentido, publicado no Diário Oficial, ou comunicado telegraficamente ao interventor, ou governador, terá força executória imediata.

12 Art. 22. [Retificação do Decreto-Lei 1202/39] Ficará suspenso o decreto-lei, ou o ato impugnado, quando no seu exame, ou no do respectivo recurso, Ihe for contrário o voto de dois terços dos membros do Departamento Administrativo. Tal suspensão poderá ser levantada pelo Presidente da República [substitui "O Ministro da Justiça" na redação anterior], sem prejuízo dos procedimentos ulteriores.

13 Art. 46. [Retificação do Decreto-Lei 1202/39] 0 interventor, ou governador, remeterá anualmente ao Presidente da República, por intermédio do Ministro da Justiça [substitui "semestralmente ao Ministro da Justiça" 
na redação anterior], um relatório de sua gestão e, englobadamente, da dos Municípios, acompanhado dos correspondentes balancetes da receita e da despesa.

14 Para a data inicial de concepção do decreto-lei, ver a entrada de 16 jan. 1939 do Diário de Vargas; para a assinatura do documento, ver a entrada de 8 abr.; para a apreensão dos interventores, 14-16 abr.; para a atuação do governador de Minas Gerais contra o Código, ver a entrada de 19 maio; para a gestão do interventor do Rio Grande do Sul, 22 maio; e para a pressão de Osvaldo Aranha, ver a entrada de 9 jun. (Vargas, 1995: $192,215,217,224,224-225$ e 230 respectivamente). Para maiores detalhes desses conflitos e tudo o que estava em jogo, ver Codato (2011: 326-328).

15 Art. 40. [Retificação do Decreto-Lei 1202/39] Só os brasileiros, natos ou naturalizados, poderão exercer funções ou cargos públicos ou empregos dos Estados ou Municípios, ou de entidades por eles criadas ou mantidas, ou de cuja manutenção sejam responsáveis.

$\S 1^{\circ}$ É lícito contratar o serviço de cientistas e técnicos estrangeiros, com funções especificadas e por tempo certo e não superior a quatro anos. Esses contratos só poderão ser celebrados com prévia e expressa autorização do Presidente da República, por intermédio do Ministro da Justiça, mediante justificação da necessidade de ser o serviço atribuído ao estrangeiro indicado, de comprovada competência na especialidade. A autorização não será concedida quando se tratar de funções de caráter administrativo, ou, ainda, de funções técnicas que não envolvam especialização definida.

$\S 2^{\circ}$ Os estrangeiros que nesta data se encontram no exercício de funções, cargos e empregos que por este artigo são reservados a brasileiros, deverão encaminhar ao Ministério da Justiça e Negócios Interiores, até 10 de agosto próximo, por intermédio das repartições onde têm exercício, os seus requerimentos de naturalização.

$\S 3^{\circ}$ As naturalizações a que se refere o parágrafo anterior processar-se-ão no Ministério da Justiça e Negócios Interiores, independentemente da justificação judicial e dos prazos constantes do Decreto-Lei no 389, de 25 de abril de 1938, e na forma das instruções do respectivo Ministro de Estado, que disporá quanto aos requisitos exigíveis dentre os enumerados por aquele decreto-lei.

$\S 4^{\circ}$ Ficarão ipso facto revogados os atos de nomeação ou designação e rescindidos os instrumentos de contrato:

1) se, findo o prazo do $\S 2^{\circ}$, não tiverem sido apresentados os requerimentos;

2) se não forem cumpridos os despachos nos prazos indicados;

3) se a naturalização não for concedida. [nova redação, substitui a anterior; o § 40 foi acrescentado].

16 Art. 6o [Retificação do Decreto-Lei 1202/39] Compete ao interventor, ou governador, especialmente: [...]

IV - elaborar os decretos-lei e sancioná-los depois de aprovados pelo Departamento Administrativo;

V - expedir decretos-lei, independente de aprovação prévia do Departamento Administrativo, em caso da calamidade ou necessidade de ordem pública, sujeitando a posteriori o seu ato à aprovação do Presidente da República [incisos acrescentados à redação anterior].

17 Art. 9o [Retificação do Decreto-Lei 1202/39] 0 interventor, ou governador, será processado e julgado, nos crimes de responsabilidade, pelo Tribunal de Apelação do Estado, importando sempre a sentença condenatória a perda do cargo e a inabilitação para exercer função pública pelo prazo de 2 a 10 anos.

Parágrafo único. 0 processo e o julgamento desses crimes serão regulados em lei especial [parágrafo acrescentado à redação original]. 
18 Art. 12. [Retificação do Decreto-Lei 1202/39] Compete ao prefeito: [...]

III - organizar o projeto de orçamento do Município e sancioná-lo, depois de revisto pelo interventor, ou governador, que o remeterá ao Departamento Administrativo para os efeitos do art. 17, letra b; [texto acrescentado a partir de "depois de revisto"]

19 Art. 17. [Retificação do Decreto-Lei 1202/39] Compete ao Departamento Administrativo: [...]

e) proceder ao estudo dos serviços, departamentos, repartições e estabelecimentos do Estado e dos Municípios, com o fim de propor [substitui "determinar" na redação original], do ponto de vista da economia e eficiência, as modificações que devam ser feitas nos mesmos, sua extinção, distribuição e agrupamento, dotações orçamentárias, condições e processos de trabalho; [...]

Parágrafo único. Das decisões do Departamento, o interventor, ou governador, poderá recorrer para o Presidente da República [parágrafo acrescentado à redação original].

20 Art. 14. [Retificação do Decreto-Lei 1202/39] As nomeações de membros do Departamento Administrativo não podem recair em quem: [...]

[Suprimido o parágrafo único da redação anterior, que prescrevia: "Dentro de um ano contado da data em que cessarem as suas funções, nenhum membro do Departamento poderá ser nomeado para cargos referidos neste artigo nem aceitar emprego ou função, ou gozar de favores a que ele se refere. Pena de nulidade do ato de nomeação, e, quando for o caso, rescisão do contrato da empresa com o poder público, ou cassação das vantagens concedidas; para o beneficiário do ato ilegal, inabilitação para o exercício da função pública pelo prazo de 2 a 10 anos"].

21 A troca foi uma sugestão de Goffredo da Silva Telles Jr. ao ministro da Justiça, Marcondes Filho. De acordo com Goffredo Jr., assessor informal da Presidência do Departamento paulista, a nova palavra daria uma ideia melhor tanto das funções legislativas (técnicas), quanto das funções representativas (políticas) que o aparelho possuía. Comunicação pessoal. São Paulo, 11 jul. 1996.

22 Art. 6o [Decreto-Lei 1202/39 modificado pelo Decreto-Lei 5511/43] Compete ao interventor, ou governador, especialmente:

I - organizar a administração do Estado e dos Municípios, de acordo com o disposto para os serviços da União, no que for aplicável;

II - legislar para os municípios constituídos em prefeituras sanitárias, em estâncias climatérmicas ou hidrominerais;

III - organizar o projeto do orçamento do Estado e sancioná-lo depois de aprovado pelo Conselho Administrativo;

IV - fixar, em decreto-lei, o efetivo da força policial, mediante prévio exame do Conselho Administrativo e aprovação do Presidente da República;

V-elaborar os projetos de decretos-lei e sancioná-los depois de aprovados pelo Conselho Administrativo;

VI - expedir decretos-lei, independentemente de aprovação prévia do Conselho Administrativo, em casos de calamidade ou necessidade da ordem pública, sujeitando a posteriori o seu ato à aprovação do Presidente da República, depois de emitido parecer por aquele conselho. 
§ 100 preparo da proposta orçamentaria será feito sob a imediata orientação e supervisão do interventor, ou governador, obedecidas as normas financeiras e de contabilidade estabelecidas pela união para os estados e municípios.

$\S 2$ 2№s estados em que já tenha sido criado ou em que se crie o departamento do serviço público, caberá a este órgão o preparo da proposta orçamentária [modificações indicadas em itálico].

23 Art. 17. [Decreto-Lei 1202/39 modificado pelo Decreto-Lei 5511/43] Compete ao Conselho Administrativo:

a) aprovar ou rejeitar, parcial ou integralmente, com as emendas julgadas necessárias, os projetos de decretos-lei que devam ser baixados pelo interventor, ou governador, ou prefeito;

b) opinar sobre os projetos de que trata a alínea anterior, quando tenham a sua vigência condicionada à aprovação do presidente da república;

c) aprovar, com as alterações julgadas necessárias, os projetos de orçamento do Estado e dos Municípios, encaminhados pelo interventor, ou governador, ou prefeito;

d) fiscalizar a execução orçamentaria no Estado, em colaboração com o departamento do serviço público, no estado onde existir este órgão, e nos Municípios, e representar ao Ministério da Justiça e Negócios Interiores, ou ao interventor, ou governador, conforme o caso, sobre as irregularidades observadas;

e) receber e informar os recursos dos atos do interventor, ou governador, na forma dos arts. 19 e 22;

f) propor ao interventor, ou governador, ou prefeito quaisquer modificações que visem ao aperfeiçoamento dos serviços públicos no estado ou município;

g) dar parecer nos recursos dos atos dos prefeitos, quando o requisitar o interventor, ou governador.

$\S 100$ interventor, ou governador, tem o prazo de 30 dias para sancionar e promulgar os projetos de decretos-lei de sua iniciativa, de acordo com a respectiva resolução do conselho administrativo, ou desta recorrer para o presidente da república.

$\S 2$ 2 o prefeito tem o prazo de 30 dias, prorrogável por mais trinta, pelo presidente do conselho administrativo, em casos devidamente justificados, para sancionar os projetos de decretos-lei, de conformidade com a resolução do conselho administrativo, ou desta recorrer para o presidente da república, com prévia autorização do interventor, ou governador.

$\S 3$ 3o o interventor, ou governador, ou prefeito não pode deixar de se manifestar, dentro de um prazo de 90 dias, sobre as propostas de que trata a letra $f$ deste artigo.

$\S 4$ - publicado o parecer de um ou mais conselheiros sobre os projetos de decretos-lei de iniciativa do interventor, ou governador, ou prefeito, estes não poderão retirar os projetos sem a devida justificação.

$\S 5$ 5o os prazos de que trata este artigo são contados da data da publicação das resoluções do conselho na imprensa oficial do estado.

$\S 60$ salvo caso de necessidade pública, devidamente justificado, nenhum projeto de decreto-lei será submetido à consideração do conselho antes de decorrido o prazo de quarenta e oito horas a partir da publicação do respectivo parecer na imprensa oficial do estado.

$\S 70$ são nulos de pleno direito os atos baixados em desacordo com a decisão do conselho administrativo, ou sem a sua prévia audiência, nos casos em que elas forem expressamente exigidas por lei. 
§ 8 o o interventor, ou governador, dentro do prazo de noventa dias, deverá se pronunciar, perante 0 conselho administrativo, sobre a representação por este formulada contra atos de prefeitos [modificações indicadas em itálico].

24 Gofredo Teixeira da Silva Telles, discurso pronunciado por ocasião da passagem do primeiro aniversário do Departamento em 11 jul. 1940. Departamento Administrativo do Estado de São Paulo, Anais de 1940, vol. I (Sessões), 2aㅡ parte, p. 1216.

25 Congresso dos Conselhos Administrativos. O Estado de S. Paulo, 12 nov. 1943, p. 12.

26 O Estado de S. Paulo, 11 nov. 1943, p. 6.

270 Departamento das Municipalidades deveria processar os projetos de orçamento elaborados pelas 270 prefeituras do estado de São Paulo. "Por seu intermédio é que o Interventor poderá desempenhar a função árdua de proceder à revisão dos orçamentos municipais e remetê-los ao Departamento Administrativo, entendendo-se com ele constantemente a fim de imprimir a sua orientação pessoal às soluções exigidas em cada caso." Departamento Administrativo do estado de São Paulo, Anais de 1939, vol. I (Sessões), 1a parte, p. 566; Para mais detalhes, v. o Decreto n. 10495 de 19 set. 1939 e as emendas do relator (p. 568 e segs.).

28 Ver O Estado de S. Paulo, 2 nov. 1943, p. 12; 10 nov. 1943, p. 7; e 11 nov. 1943, p. 6; para o resultado dos debates das subcomissões e suas proposições aprovadas, ver Conferência dos Conselhos Administrativos dos estados. O Estado de S. Paulo, 14 nov. 1943, p. 8.

29 Congresso dos Conselhos Administrativos. O Estado de S. Paulo, 12 nov. 1943, p. 12.

30 Decreto-Lei 1202 de 8 de abril de 1939, art. 17. 0 art. 19 a que alínea "c" faz referência dispunha 0 seguinte: "Caberá recurso, respectivamente para o Presidente da República, ou para o Interventor, ou Governador, dos atos do Interventor, ou Governador, ou dos Prefeitos que: a) atentarem contra a Constituição e as leis; b) importarem concessão ou contrato de serviço público, ou sua rescisão". 0 art. 22 estabelecia: "Ficará suspenso o decreto-lei, ou o ato impugnado, quando no seu exame, ou no do respectivo recurso, lhe for contrário o voto de dois terços dos membros do Departamento Administrativo. Tal suspensão poderá ser levantada pelo Presidente da República, sem prejuízo dos procedimentos ulteriores".

31 Essas medidas eram quase sempre de ajustes administrativos ou se passavam por isso. Miguel Reale recorda que a autonomia orçamentária efetiva da Universidade de São Paulo resultou do Decreto-Lei 13855, de 29 fev. 1944, mediante processo relatado por ele no DAESP, que transformou a universidade em "autarquia". Ver Miguel Reale (1994: 25).

32 Para a ideia, ver (Martins, 1976: 159).

33 Art. 6a [Decreto-Lei 1202/39 modificado pelo Decreto-Lei 7518/45] Compete ao interventor, ou governador, especialmente: [...]

VI - expedir decretos-lei, independentemente de aprovação prévia do Conselho Administrativo, em casos de calamidade ou necessidade da ordem pública.

34 Art. 6ㅇ, §§ 3ํa 5o (excluídos).

35 Art. 32 [Decreto-Lei 1202/39 modificado pelo Decreto-Lei 7518/45] Dependerão de aprovação do Presidente da República os projetos de decreto-lei que dispuserem sobre as seguintes matérias:

I - processo judicial ou extrajudicial;

II - definição do pequeno produtor, para os efeitos do art. 23, no 1, letra d, da Constituição; 
III - divisão administrativa e organização judiciária;

IV - impostos ou taxas de exportação;

V - distribuição de impostos aos Municípios, na forma do art. 28 da Constituição;

$\mathrm{VI}$ - concessão de isenções tributárias[, privilégios ou garantias de juros pelos Estados ou Municípios];

VII - impostos ou taxas estaduais, desde que se trate de nova tributação ou de majoração, excetuadas as taxas relativas aos serviços industriais, explorados ou concedidos pelo estado;

VIII - criação de impostos e taxas municipais, excetuadas as taxas relativas aos serviços industriais, explorados ou concedidos pelo município, e as de limpeza pública e particular, calçamento e receita dos bens particulares;

IX - as matérias constantes dos arts. 90 a 96 e 103 a 110 da Constituição.

§ 10 São nulos de pleno direito os atos praticados com infração do disposto neste artigo. A declaração de nulidades poderá ainda ser feita de ofício, ou mediante representação de qualquer interessado, por decreto-lei federal.

§ 2ำA isenção do imposto de transmissão de propriedade, em benefício de instituiçã̃o de notória utilidade pública, poderá ser concedida mediante decreto-lei, aprovado pelo conselho administrativo [modificações indicadas em itálico].

36 Foram excluídos da competência do presidente da República os projetos de decreto-lei que dispusessem sobre os seguintes temas: I - o bem-estar, a ordem, a tranquilidade e a segurança pública; |I - as comunicações e o transporte por via férrea, d'água e aérea, ou estradas de rodagem; III - arrendamento, concessão, ou autorização para exploração de minas, metalurgia, energia hidráulica, águas, florestas, caça e pesca, e o seu regime ou regulamentação; IV - riquezas de subsolo, mineração, metalurgia, águas, energia hidroelétrica, florestas, caça e pesca, e sua exploração; $V$ - rádio-comunicação, regime de eletricidade; VI - regime das linhas para as correntes de alta tensão; VII - escolas de grau secundário e superior, e regulamentação, no todo ou em parte, do ensino de qualquer grau; VIII - saúde pública; higiene do trabalho; IX - assistência pública, obras de higiene popular, casas de saúde, clínicas, estações de clima e fontes medicinais; $X$ - fiscalização administrativa e policial de teatros, cinematógrafos e demais divertimentos públicos; $X \mathrm{X}$ - fixação do efetivo da força policial, corpo de bombeiros, guarda civil e corporações de natureza semelhante, seu armamento, despesa e organização; XIII - organizações públicas com o fim de conciliação extrajudiciária dos litígios, ou sua decisão arbitral; XIV - medidas de polícia para a proteção das plantas e dos rebanhos contra as moléstias ou agentes nocivos; XV - crédito agrícola, cooperativas entre agricultores; XX - organização dos Municípios; seu agrupamento para os fins do art. 29 da Constituição.

\section{REFERÊNCIAS BIBLIOGRÁFICAS}

BARROS, G. P. P. Princípios de administração pública. Rio de Janeiro: Livr. Jacinto, 1945.

BOURDIEU, P. La noblesse d'Etat: grandes écoles et esprit de corps. Paris: Editions de Minuit, 1989.

CAMARGO, D. D. Centralização e intervenção: padrão político e institucional do Estado Novo no Rio Grande do Sul - o Departamento Administrativo de Estado. Porto Alegre: Universidade Federal do Rio Grande do Sul, 1983. 
CAMPOS, F. Direito administrativo. Rio de Janeiro: Imprensa Nacional, 1943.

. O Estado Nacional: sua estrutura, seu conteúdo ideológico. Brasília: Senado Federal, 2001.

CAPELATO, M. H. Os arautos do liberalismo: imprensa paulista, 1920-1945. São Paulo: Brasiliense, 1989.

CASTRO, A. A Constituição de 1937. Brasília: Senado Federal, 2003.

CAVALCANTI, T. B. Tratado de Direito Administrativo - vol. I: o Estado - estrutura - organização - administração - funções. Rio de Janeiro: Livraria Editora Freitas Bastos, 1942.

CODATO, A. Intervenção estatal, centralização política e reforma burocrática: o significado dos Departamentos Administrativos no Estado Novo. Revista do Serviço Público, 62(3), 2011, p.321-339.

—. Instituições de governo, ideias autoritárias e políticos profissionais em São Paulo nos anos 1940. Revista Brasileira de Ciência Política, (11), 2013, p.143-167.

FONSECA, T. P. A evolução do direito administrativo brasileiro nos últimos 25 anos. Direito: doutrina, legislação e jurisprudência, 3(17), 1942, p.23-37.

GIDDENS, A. Elites in the British class structure. In: Stanworth, P. \& Giddens, A. (eds.). Elites and power in British society. Cambridge: Cambridge University Press, 1974.

LOEWENSTEIN, K. Brazil under Vargas. New York: The Macmillan Company, 1944.

LINDBLOM, C. E. O processo de decisão política. Brasília: Editora Universidade de Brasília, 1981.

MARTINS, L. Pouvoir et développement économique. Formation et évolution des structures politiques au Brésil. Paris: Paris Anthropos, 1976.

MENEZES, D. Direito administrativo moderno: os princípios estruturais do Estado Nacional na administração pública. Rio de Janeiro: A. Coelho Branco Filho, 1943.

PONTES DE MIRANDA, F. C. Comentários à Constituição Federal de 10 de novembro de 1937. Rio de Janeiro: Irmãos Pongetti, 1938.

RAMOS, F.A. O Departamento Administrativo do estado de São Paulo. Revista do Serviço Público, 2(1), 1943, p.43-50.

REALE, M. Minhas memórias da USP. Estudos Avançados, vol. 8, n. 22, 1994.

VARGAS, G. Getúlio Vargas: diário. São Paulo/Rio de Janeiro: Siciliano/Editora Fundação Getúlio Vargas, 1995. 